\title{
A Fuzzy Hybrid Approach for Fuzzy Process FMEA: An Application to a Spindle Manufacturing Process
}

\author{
Mehmet Ekmekçioğlu * \\ Department of Production Planning, FORD OTOSAN \\ Golcuk, Izmit, 34367, Turkey \\ Ahmet Can Kutlu \\ Department of Industrial Engineering, Istanbul Technical University \\ Macka, Istanbul, 34367, Turkey \\ Received 14 August 2011 \\ Accepted 10 May 2012
}

\begin{abstract}
Process Failure Modes and Effects Analysis (PFMEA) concept, has been developed based on the success of Failure Modes and Effects Analysis (FMEA) to include a broader analysis team for the realization of a comprehensive analysis in a short time. The most common use of the PFMEA involves manufacturing processes as they are required to be closely examined against any unnatural deviation in the state of the process for producing products with consistent quality. In a typical FMEA, for each failure modes, three risk factors; severity $(S)$, occurrence $(O)$, and detectability $(D)$ are evaluated and their multiplication derives the risk priority number (RPN). However there are many shortcomings of this classical crisp RPN calculation. This study introduces a fuzzy hybrid approach that allows experts to use linguistic variables for determining $S, O$, and $D$ for PFMEA by applying fuzzy 'technique for order preference by similarity to ideal solution' (TOPSIS) and fuzzy 'analytical hierarchy process' (AHP). An application to a spindle manufacturing process expresses the relevance of the fuzzy hybrid model in PFMEA.
\end{abstract}

Keywords: Fuzzy Process FMEA, Fuzzy AHP, Fuzzy TOPSIS, Manufacturing process.

*Corresponding author. Tel.: +90 506 7622584. E-mail: meceng3584@yahoo.com, ekmekciogl@itu.edu.tr 


\section{Introduction}

There exists a continuously increasing demand for quality products in industry and therefore manufacturing systems need to be closely monitored for any unnatural deviation in the state of the process in order to produce products with consistent quality ${ }^{1}$. The use of a quality control system can lead to the elimination of assignable causes pointed to by unnatural behaviour ${ }^{2}$. FMEA, providing a framework for cause and effect analysis of potential product or process failures ${ }^{3}$, is a widely used engineering technique for designing, identifying and eliminating known and/or potential failures, problems, errors and so on from system, design, process, and/or service before they reach the customer ${ }^{4}$.

FMEA was first used in NASA in 1963 as a formal design methodology and later Ford Motor adopted and promoted the technique in 1977 due to its obvious reliability requirements 5 . After this time, FMEA has become a powerful tool extensively employed for safety and reliability analysis of products and processes in a wide range of industries particularly in aerospace, nuclear and automotive industries ${ }^{6}$.

Based on the success of Failure Modes and Effects Analysis (FMEA), the Process Failure Modes and Effects Analysis (PFMEA) concept was developed to incorporate a broader analysis team to accomplish a thorough analysis in a short time. PFMEA takes a product or service design and considers all the steps that are necessary to be successful. The most common use of the PFMEA involves manufacturing processes. PFMEAs may be performed on new processes or to improve current processes and to maximize its value and a PFMEA should be performed as early in the manufacturing development cycle as possible.

The purpose of PFMEA is prioritizing the Risk Priority Number (RPN) of the planning process to assign the limited resources to the most serious risk item $^{5}$. Each failure mode can be evaluated by three factors as severity, likelihood of occurrence, and the difficulty of detection of the failure mode. Conventional PFMEA evaluation includes these factors each of which is assigned a value between 1 and 10 (with 1 being the best and 10 being the worst case) and the values of severity $(S)$, occurrence $(O)$, and detectability $(D)$ are multiplied to produce risk priority number (RPN) as $\mathrm{RPN}=S \times O \times D$. Then the RPN value for each failure mode is ranked to find out the failures with higher risks $^{7}$.

The classical crisp valuation of RPN has been significantly criticized for a many reasons most of which are shown below $6,7,8,9,10,11,12,13,14$.

- The risk factors $S, O$ and $D$ are accepted equally important ignoring their relative importance among them.

- Different combinations of $S, O$ and $D$ may produce exactly the same value of RPN, although their hidden risk implications may be totally different. For instance, two different failures with the $S, O$ and $D$ values of 2, 4, 3 and 3,8,1 respectively, have the same RPN value of 24 .

- Precisely evaluation of $S, O$ and $D$ is mostly difficult. However linguistic terms can be adopted to express much information in PFMEA.

- While calculating RPN, the use of multiplication method is considered questionable as it is strongly sensitive to variations in criticality factor evaluations.

In the comparison of the classical and the fuzzy approach, the fuzzy approach has an advantage of allowing the conduction of risk evaluation and prioritization based on the knowledge of the experts ${ }^{15}$.

$\mathrm{Xu}$, Tang, Xie, Ho, and Zhu (2002) introduce two reasons for considering the fuzzy logic approach; firstly natural language is taken in PFMEA-related information as it is easy and plausible for fuzzy logic to deal with as it is based on human language and can be built on top of the experience of experts. Secondly as fuzzy logic allows use of imprecise data; it enables the treatment of many states.

Moreover, fuzzy PFMEA, allowing both quantitative data and vague and qualitative information to be used and managed in a consistent manner, makes it possible to combine severity, occurrence and detectability in a more flexible structure ${ }^{11,17}$.

In this study, a hybrid fuzzy approach is proposed for PFMEA. It firstly applies a model of Buckley's ${ }^{18}$ fuzzy AHP integrated with Chen's ${ }^{19}$ fuzzy TOPSIS separately for each process function. Later the obtained closeness coefficients are multiplied by the weights of the process functions for finding the global weight scores. Finally the potential failures are ranked according to their global weight scores. 
The rest of the paper is organized as follows: In Section 2, Literature Reviews of Fuzzy FMEA, Fuzzy AHP and Fuzzy TOPSIS are expressed. In Section 3, a fuzzy hybrid approach is proposed for fuzzy PFMEA. In Section 4, the proposed methodology is applied to a spindle manufacturing process in a firm producing aluminum parts and dies for automotive and white-good industries considering the process functions of a spindle manufacturing process. A sensitivity analysis is also realized. Finally, conclusions are given.

\section{Literature Review}

\subsection{Fuzzy FMEA}

There are significant efforts have been made in FMEA literature to overcome the shortcomings of the traditional RPN ${ }^{14}$. The studies about FMEA considering fuzzy approach use the experts who describe the risk factors $S, O$, and $D$ by using the fuzzy linguistic terms. The linguistic variables were used for evaluating three risk factors $S, O$, and $D$ as an interpretation of the traditional ten-point scale (1-10) FMEA factor scores.

In the fuzzy FMEA literature, the studies have mostly concerned with the fuzzy rule-base approach by using if-then rules $3,7,15,16,17,20,21,22$. After the assignments of the linguistic terms to the factors, if-then rules were generated taking the linguistic variables as inputs to evaluate the risks. The outputs of the fuzzy inference system were variously named as risk $^{3,21}$, the critically failure mode $^{16}$, priority for attention ${ }^{7}$, and fuzzy $\mathrm{RPN}^{16,22}$ in the fuzzy FMEA studies which consider the fuzzy rule-base approach.

Braglia and Bevilacqua $(2000)^{10}$ drew attention to the doubts remained due to the difficulties in defining many rules and membership functions required by this methodology considering the applicability of the real industrial cases. They proposed the use of AHP for obtaining the rules for a particular fuzzy criticality assessment model to overcome this problem. Besides, AHP is employed in another study to cope with multiple criteria situations involving intuitive, rational, qualitative and quantitative aspects for the evaluation of the final ranking for every failure cause and this new approach is called multi-attribute failure mode analysis $(\mathrm{MAFMA})^{23}$.

Braglia and Bevilacqua $(2000)^{10}$ criticize that the failure modes characterized by the fuzzy if-then rules could not be prioritized or ranked and there is no way to incorporate the relative importance of risk factors into the fuzzy inference system by using fuzzy if-then rules. Therefore they develop a new fuzzy logic approach where fuzzy risk priority numbers (FRPNs) are defined as fuzzy weighted geometric means of the fuzzy ratings for $S, O$, and $D$ and can be computed using alpha-level sets and linear programming models.

The fuzzy analytic hierarchy process (FAHP) approach was considered by Hua, Hsu, Kuo, and Wua $(2009)^{24}$ for evaluating the relative weightings of the risk factors of FMEA to analyze of the risks of green components in compliance with the European Union (EU) the Restriction of Hazardous Substance (RoHS) directive in the incoming quality control (IQC) stage. In the study, Severity factor was explained by two criteria and with considering the Occurrence and the Detection factors, the FAHP was utilized to determine the weights of four criteria by two experts. The traditional FMEA was modified to form green component risk priority number (GC-RPN) for the calculation of the risks with regard to each category of green components. GC-RPN was formulated by the sum of the terms of products of the factor scores and weights.

Hua, Hsu, Kuo, and Wua (2009) ${ }^{11}$ proposed a fuzzy TOPSIS approach for Failure Mode, Effects and Criticality Analysis (FMECA). The fuzzy version of TOPSIS was applied allowing the traditional FMECA factors $\mathrm{O}, \mathrm{S}$, and $\mathrm{D}$ and their equally important weights to be evaluated using triangular fuzzy numbers.

\subsection{Fuzzy $A H P$}

AHP is one of the well-known multi-criteria decision making techniques that was first proposed by Saaty $(1980)^{25}$. The classical AHP takes into consideration the definite judgments of decision makers ${ }^{26}$. Although the classical AHP includes the opinions of experts and makes a multiple criteria evaluation, it is not capable of reflecting human's vague thoughts ${ }^{27}$.

As the uncertainty of information and the vagueness of human feeling and recognition, it is difficult to provide exact numerical values for the criteria and to make evaluations which exactly convey the feeling and recognition of objects for decision makers. Therefore, most of the selection parameters cannot be given precisely. Thus experts may prefer intermediate judgments rather than certain judgments. So the fuzzy set theory makes the comparison process more flexible and capable to explain experts' preferences ${ }^{28}$. 
Different methods for the fuzzification of AHP have been proposed in the literature. AHP is firstly fuzzified by Laarhoven and Pedrycz $(1983)^{29}$, and in this study, fuzzy ratios which were defined by triangular membership functions were compared. The comparison ratios based on trapezoidal membership functions are used in Buckley's approach ${ }^{18}$. Another approach was introduced by Chang ${ }^{30}$ for handling fuzzy AHP, with the use of triangular fuzzy numbers for pair-wise comparison scale of fuzzy AHP, and the use of the extent analysis method for the synthetic extent values of the pair-wise comparisons. A fuzzy objective and subjective method based on fuzzy AHP was proposed by Kahraman, Ulukan, and Tolga $(1998)^{31}$. Kulak and Kahraman $(2005)^{32}$ made a selection among the transportation companies by using fuzzy axiomatic design and fuzzy AHP. They developed fuzzy multiattribute axiomatic design approach and compared it with fuzzy AHP.

\subsection{Fuzzy TOPSIS}

TOPSIS, one of the classical Multi-criteria decision making methods, was developed by Hwang and Yoon $(1981)^{33}$. It is based on the concept that the chosen alternative should have the shortest distance from the positive ideal solution (PIS) and the farthest from the negative ideal solution (NIS). TOPSIS also provides an easily understandable and programmable calculation procedure. It has the ability of taking various criteria with different units into account simultaneously ${ }^{34}$.

A number of fuzzy TOPSIS methods have been developed in recent years. Fuzzy numbers to establish fuzzy TOPSIS was first applied in Chen and Hwang (1992). ${ }^{35}$ A fuzzy TOPSIS method developed by Triantaphyllou and Lin $(1996)^{36}$ where relative closeness for each alternative is evaluated based on fuzzy arithmetic operations. Chen (2000) ${ }^{19}$ extends the TOPSIS method to fuzzy group decision making situations by considering triangular fuzzy numbers and defining crisp Euclidean distance between two fuzzy numbers. The methodology proposed by Chen $(2000)^{19}$ is further improved in some studies ${ }^{37-38}$. In addition the fuzzy TOPSIS method is extended based on alpha level sets with interval arithmetic ${ }^{39-40}$.

Fuzzy TOPSIS has been introduced for various multi-attribute decision-making problems. Fuzzy TOPSIS is used for plant location selection ${ }^{41}$ and for supplier selection ${ }^{42}$. Fuzzy TOPSIS also is utilized for industrial robotic system selection ${ }^{43}$. Ekmekcioglu, Kaya, and Kahraman (2010) $)^{34}$ used a modified fuzzy TOPSIS to select municipal solid waste disposal method and site. Another modified fuzzy TOPSIS is used for selection of the best energy technology alternative ${ }^{44}$. Fuzzy TOPSIS is used for modeling consumer's product adoption process. ${ }^{45}$

\section{Fuzzy Hybrid Approach for Fuzzy PFMEA}

To overcome the shortcomings of crisp PFMEA, a fuzzy multi-criteria approach is proposed for fuzzy PFMEA in this paper. For determining the importance of failure modes a modified fuzzy approach integrating the Buckley's fuzzy AHP and Chen's fuzzy TOPSIS is used. The fuzzy PFMEA approach is performed separately for each process function since all the process functions may have different $S, O$, and $D$ importance values. In this stage, failures are determined in the process functions by the experts and then Buckley's fuzzy AHP is utilized to determine the weight vector of three risk factors; severity, occurrence and detectability. Subsequently, by using the linguistic scores of risk factors for each failure modes, and the weight vector of risk factors, Chen's fuzzy TOPSIS is utilized. The potential failure modes for each process functions are obtained and ranked according to the results of their closeness coefficient. Later the closeness coefficients are multiplied by the weights of the process functions for finding the global weight scores. Finally the potential failures are ranked according to their global weight scores.

\subsection{Buckley's Fuzzy AHP}

Buckley $(1985)^{18}$ uses the geometric mean method to derive fuzzy weights and performance scores. This method is selected in the study due to its easy use to extend to the fuzzy case and guarantee a unique solution to the reciprocal comparison matrix. The weight assessing method by geometric mean is chosen for its simplicity and ease in its application to the fuzzy case. The positive reciprocal comparison matrix of criteria weights is given as:

$$
C=\left[\begin{array}{cccc}
C_{11} & C_{12} & \cdots & C_{1 n} \\
C_{21} & C_{22} & \cdots & C_{2 n} \\
\vdots & & & \vdots \\
C_{n 1} & C_{n 2} & \cdots & C_{n n}
\end{array}\right]
$$


The geometric mean of each row is calculated as:

$$
z_{j}=\left[\prod_{k=1}^{n} C_{j k}\right]^{1 / n} \text { for } j, k=1,2, \ldots, n
$$

where $C_{j k}$ evaluation of the decision maker on the pairwise importance comparison of $j^{\text {th }}$ and $k^{\text {th }}$ criteria.

The weight $\mathrm{w}_{\mathrm{j}}$ is calculated as:

$$
w_{j}=\frac{z_{j}}{z_{1}+z_{2}+\ldots+z_{n}}, \quad \forall j .
$$

To facilitate the calculation of fuzzy weights, the following arithmetic operations of trapezoidal fuzzy numbers are presented. A trapezoidal fuzzy number (TrFN) can be defined as $\tilde{m}=(a, b, c, d)$ where $0 \leq a \leq b \leq c \leq d$

In the following, Buckley's (1985) method $^{18}$ is explained in the following steps:

Step 1: Evaluate the relative importance of the criteria using pair-wise comparisons. The experts are required to provide their judgments on the basis of their knowledge and expertise. The experts' linguistic preferences based on Saaty ${ }^{25}$ scale are converted into trapezoidal fuzzy numbers using Table 1. Although this scale is criticized in some papers ${ }^{46,47}$, many fuzzy AHP studies in the literature use fuzzy numbers based on this scale ${ }^{27,28,29,31,32,34}$. The scale and $\mathrm{TrFNs}$ used in this paper is modified from the study of Tolga and Kahraman $(2011)^{48}$ since an optimal trapezoidal fuzzy numerical scale in AHP has not been found in the literature.

Table 1. Fuzzy evaluation scores for the weight vector

\begin{tabular}{lc}
\hline Linguistic terms & Fuzzy score \\
\hline Absolutely Strong (AS) & $(2,2.25,2.75,3)$ \\
Very Strong (VS) & $(1.5,1.75,2.25,2.5)$ \\
Fairly Strong (FS) & $(1,1.25,1.75,2)$ \\
Slightly Strong (SS) & $(1,1.25,1.25,1.5)$ \\
Equal (E) & $(1,1,1,1)$ \\
Slightly Weak (SW) & $(2 / 3,1,1,1)$ \\
Fairly Weak (FW) & $(1 / 2,2 / 3,0.85,1)$ \\
Very Weak (VW) & $(2 / 5,1 / 2,3 / 5,2 / 3)$ \\
Absolutely Weak (AW) & $(1 / 3,2 / 5,0.45,0.5)$ \\
\hline
\end{tabular}

Step 2: Aggregate experts' individual preferences into group preference by applying the fuzzy trapezoidal averaging operator, which is defined by

$$
\widetilde{C}_{j k}=\frac{1}{K}\left[\widetilde{C}_{j k}^{1}(+) \widetilde{C}_{j k}^{2}(+) \ldots(+) \widetilde{C}_{j k}^{K}\right]
$$

where $K$ is the number of experts and $\widetilde{C}_{j}^{K}$ is the evaluation of the $K^{\text {th }}$ decision maker on the pairwise importance comparison of $j^{\text {th }}$ and $k^{\text {th }}$ criteria.

Step 3. Obtain the fuzzy weights $\widetilde{w}_{j}$. The derivation of $\widetilde{z}_{j}$ values (Eq. 2) and fuzzy weights $\widetilde{w}_{j}$ (Eq. 3) can be detailed as follows. Let,

$$
a_{j}=\left[\prod_{j=1}^{n} \tilde{a}_{j k}\right]^{1 / n}
$$

and

$$
a=\sum_{j=1}^{n} a_{j} .
$$

Similarly, $b_{\mathrm{j}}$ and $b, c_{\mathrm{j}}$ and $c, d_{\mathrm{j}}$ and $d$ can be defined. The fuzzy weight $w_{\mathrm{j}}$ is determined as

$$
w_{j}=\left(\frac{d_{j}}{d}, \frac{c_{j}}{c}, \frac{b_{j}}{b}, \frac{a_{j}}{a}\right), \text { each } \mathrm{j}
$$

Step 4. Defuzzify and normalize the trapezoidal fuzzy weights. To defuzzify the TrFN in Eq. (7), Eq. (8) is used:

$$
w_{j}^{\prime}=\frac{\frac{a_{j}}{d}+2\left(\frac{b_{j}}{c}+\frac{c_{j}}{b}\right)+\frac{d_{j}}{a}}{6}
$$

Now, to normalize the crisp weights Eq. (9) is used:

$$
w_{j}=\frac{w_{j}^{\prime}}{\sum_{j=1}^{n} w_{j}^{\prime}}, \quad j=1,2, \ldots, n
$$

After the deffuzzification of each value in the matrix, Consistency Ratio (CR) of the matrix can easily be calculated and checked whether $\mathrm{CR}$ is smaller than .10 or not.

\subsection{Chen's Fuzzy TOPSIS}

In the following, Chen's fuzzy TOPSIS method ${ }^{19}$ in which linguistic preferences can easily be converted to fuzzy numbers which are allowed to be used in calculations $^{36-44}$ is explained:

It is suggested that the decision makers use linguistic variables to evaluate the ratings of alternatives with respect to criteria. Table 2 gives the linguistic scale for evaluation of the alternatives. Assuming that a decision group has $\mathrm{K}$ people, the ratings of alternatives with respect to each criterion can be calculated as;

$$
\tilde{x}_{i j}=\frac{1}{K}\left[\tilde{x}_{i j}^{1}(+) \tilde{x}_{i j}^{2}(+) \ldots(+) \tilde{x}_{i j}^{K}\right]
$$


where $\tilde{x}_{i j}^{K}$ is the rating of the $K^{\text {th }}$ decision maker for $i^{\text {th }}$ alternative with respect to $j^{\text {th }}$ criterion. ${ }^{21}$

Table 2. Fuzzy evaluation scores for the alternatives.

\begin{tabular}{lc}
\hline Linguistic terms & Fuzzy score \\
\hline Very Poor (VP) & $(0,0,1)$ \\
Poor (P) & $(0,1,3)$ \\
Medium Poor (MP) & $(1,3,5)$ \\
Fair (F) & $(3,5,7)$ \\
Medium Good (MG) & $(5,7,9)$ \\
Good (G) & $(7,9,10)$ \\
Very Good (VG) & $(9,10,10)$ \\
\hline
\end{tabular}

Obtaining weights of the criteria and fuzzy ratings of alternatives with respect to each criterion, the fuzzy multi-criteria decision-making problem can be expressed in matrix format as,

$$
\begin{gathered}
D=\left[\begin{array}{cccc}
\tilde{x}_{11} & \tilde{x}_{12} & \cdots & \tilde{x}_{1 n} \\
\vdots & \vdots & \cdots & \vdots \\
\tilde{x}_{m 1} & \tilde{x}_{m 2} & \cdots & \tilde{x}_{m n}
\end{array}\right], \\
W=\left[w_{1}, w_{2}, \ldots, w_{n}\right], \quad j=1,2, \ldots, n,
\end{gathered}
$$

where $\tilde{x}_{i j}$ is the rating of the alternative $A_{i}$ with respect to criterion $j$ (i.e. $C_{j}$ ) and $w_{j}$ denotes the importance weight of $C_{j}$. These linguistic variables can be described by triangular fuzzy numbers: $\tilde{x}_{i j}=$ $\left(a_{i j}, b_{i j}, c_{i j}\right)$. To avoid the complicated normalization formula used in classical TOPSIS, the linear scale transformation is used here to transform the various criteria scales into a comparable scale. Therefore, we can obtain the normalized fuzzy decision matrix denoted by $\tilde{R}$.

$$
\tilde{R}=\left[\tilde{r}_{i j}\right]_{m x n},
$$

where $B$ and $C$ are the set of benefit criteria and cost criteria, respectively, and

$$
\begin{aligned}
& \tilde{r}=\left(\frac{\tilde{a}_{i j}}{c_{j}^{*}}, \frac{\tilde{b}_{i j}}{c_{j}^{*}}, \frac{\tilde{c}_{i j}}{c_{j}^{*}}\right), \quad j \epsilon B ; \\
& \tilde{r}=\left(\frac{a_{j}^{-}}{c_{i j}}, \frac{a_{j}^{-}}{b_{i j}}, \frac{a_{j}^{-}}{a_{i j}}\right), \quad j \epsilon C ; \\
& c_{j}^{*}=\max _{i} c_{i j} \quad \text { if } j \epsilon B ; \\
& a_{j}^{-}=\min _{i} a_{i j} \quad \text { if } j \epsilon C .
\end{aligned}
$$

The normalization method mentioned above is to preserve the property that the ranges of normalized triangular fuzzy numbers belong to $[0 ; 1]$.
Considering the different importance of each criterion, we can construct the weighted normalized fuzzy decision matrix as

$$
\tilde{V}=\left[\tilde{v}_{i j}\right]_{m x n}, \mathrm{i}=1,2, \ldots, \mathrm{m} ; \mathrm{j}=1,2, \ldots, \mathrm{n}
$$

where

$$
\tilde{v}_{i j}=\tilde{r}_{i j}(.) d\left(C_{j}\right)
$$

According to the weighted normalized fuzzy decision matrix, we know that the elements $\tilde{v}_{i j} \forall i, j$ are normalized positive triangular fuzzy numbers and their ranges belong to the closed interval $[0,1]$. Then, we can define the fuzzy positive-ideal solution $\left(F P I S, A^{*}\right)$ and fuzzy negative-ideal solution $\left(F P I S, A^{-}\right)$as

$$
\begin{aligned}
A^{*} & =\left(\tilde{v}_{1}^{*}, \tilde{v}_{2}^{*}, \ldots, \tilde{v}_{n}^{*}\right), \\
A^{-} & =\left(\tilde{v}_{1}^{-}, \tilde{v}_{2}^{-}, \ldots, \tilde{v}_{n}^{-}\right),
\end{aligned}
$$

where

$$
\tilde{v}_{j}^{*}=(1,1,1) \text { and } \tilde{v}_{j}^{-}=(0,0,0), \mathrm{j}=1,2, \ldots, \mathrm{n} .
$$

The distance of each alternative from $A^{*}$ and $A^{-}$can be currently calculated as

$$
\begin{array}{ll}
d_{i}^{*}=\sum_{j=1}^{n} d\left(\tilde{v}_{i j}, \tilde{v}_{j}^{*}\right), & \mathrm{i}=1,2, \ldots, \mathrm{m}, \\
d_{i}^{-}=\sum_{j=1}^{n} d\left(\tilde{v}_{i j}, \tilde{v}_{j}^{-}\right), & \mathrm{i}=1,2, \ldots, \mathrm{m},
\end{array}
$$

where $d(.,$.$) is the distance measurement between$ two fuzzy numbers calculating with the following formula:

$$
d(\tilde{\rho}, \tilde{\tau})=\sqrt{\frac{1}{3}\left[\left(\rho_{1}-\tau_{1}\right)^{2}+\left(\rho_{2}-\tau_{2}\right)^{2}+\left(\rho_{3}-\tau_{3}\right)^{2}\right]}
$$

where $\tilde{\rho}=\left(\rho_{1}, \rho_{2}, \rho_{3}\right)$ and $\tilde{\tau}=\left(\tau_{1}, \tau_{2}, \tau_{3}\right)$ are two triangular fuzzy numbers.

A closeness coefficient is defined to determine the ranking order of all alternatives once the $\tilde{d}_{j}^{*}$ and $\tilde{d}_{j}^{-}$of each alternative $A_{i}(\mathrm{i}=1,2, \ldots, \mathrm{m})$ are calculated. The closeness coefficient of each alternative is calculated as

$$
C C_{i}=\frac{\tilde{d}_{j}^{-}}{\tilde{d}_{j}^{*}+\tilde{d}_{j}^{-}}, i=1,2, \ldots, m
$$

Obviously, an alternative $A_{i}$ is closer to the $\left(\mathrm{FPIS}, \mathrm{A}^{*}\right.$ ) and farther from (FPIS, $\mathrm{A}^{-}$) as $\mathrm{CC}_{\mathrm{i}}$ approaches to 1 . Therefore, according to the closeness coefficient, we can determine the ranking order of all alternatives and select the best one from among a set of feasible alternatives. 


\subsection{Proposed Methodology}

In this study firstly, in a spindle manufacturing process, the process functions are defined and the weights of their importance are obtained by pair-wise comparisons according to the opinions of the experts by utilizing Fuzzy AHP method. Then a fuzzy approach, allowing experts to use linguistic variables for determining $S, O$, and $D$, is considered for PFMEA by applying fuzzy TOPSIS integrated with fuzzy AHP. The fuzzy PFMEA approach is performed separately for each process function since all the process functions may have different $S, O$, and $D$ importance values. In this stage, failures are determined in the process functions by the experts and then Buckley's fuzzy AHP is utilized to determine the weight vector of three risk factors; severity, occurrence and detectability. Subsequently, by using the linguistic scores of risk factors for each failure modes, and the weight vector of risk factors, Chen's fuzzy TOPSIS is utilized. The potential failure modes for each process functions are obtained and ranked according to the results of their closeness coefficient. Later the closeness coefficients are multiplied by the weights of the process functions for finding the global weight scores. Finally the potential failures are ranked according to their global weight scores.

To sum up; global weight scores of predefined failure modes are calculated and failure modes are ranked according to these global weight scores through succeeding the 4 main steps. These main steps of the proposed fuzzy PFMEA model are illustrated by Fig. 1. First step covers the process of first type of data collection for pair-wise comparison of process functions and the collected data is converted to the importance weights of the process functions by using fuzzy AHP methodology. In the second step, a new type of data is collected for pair-wise comparison of risk factors $S, O$, and $D$ with respect to process functions and the fuzzy AHP methodology is utilized to calculate the weights of the risk factors for each process function. The third step involves a third type of data collection from the experts. After the determination of the failure modes, experts evaluate failure modes with respect to risk factors for each process function. The evaluation data is used in fuzzy TOPSIS methodology by integrating with the values of the weights of the risk factors which are calculated in step 2. Fuzzy TOPSIS method is implemented for each process function and the outcomes are the closeness coefficient values obtained for each failure mode for each process function. In the fourth step, since all the process functions have different importance effects in the total process quality, the values of closeness coefficients of each failure mode is multiplied by the weights of the process functions which are calculated in step 1 to determine the global weights of the failure modes. Finally the global weights are ranked to find the most risky failure modes in the process quality. 4 main steps are given in more detail in the following:

Step1:

-The process functions are identified by a group of experts.

-Appropriate linguistic variables for importance of each process functions are determined.

-A pair-wise comparison matrix for importance of the process functions is constructed, and experts' linguistic evaluations are aggregated to get a mean value for each pair-wise comparison.

-Consistency of pair-wise comparison matrix for the process functions according to their importance is checked after the defuzzification of each value in the matrix according to graded mean integration approach.

-Buckley's approach is used to obtain the weights of the process functions.

Step2:

-A group of experts identifies the failure modes of each process functions.

-Appropriate linguistic variables for importance of risk factors of each process functions are determined.

-For each process function, a pair-wise comparison matrix for risk factors is constructed, and experts' linguistic evaluations are aggregated to get a mean value for each pair-wise comparison.

-Consistency of pair-wise comparison matrix for risk factors for each process function is checked after the defuzzification of each value in the matrix according to graded mean integration approach.

-Buckley's approach is used to obtain the weights of the risk factors for each process function.

Step3:

-Experts' linguistic evaluations of each failure mode with respect to risk factors are aggregated to get a mean value.

-Fuzzy decision matrix and the normalized fuzzy decision matrix for each process function are constructed for the implementation of TOPSIS. 
-Weighted normalized fuzzy decision matrix for each process function is constructed.

-For each process function FPIS and FNIS are determined.

-The distance of each failure mode from FPIS and FNIS are calculated, respectively.

-The closeness coefficient of each failure mode is calculated.

Step4:
-The closeness coefficients are multiplied by the weights of the process functions. Later obtained values are normalized for finding the global weight scores.

-The potential failures are ranked according to their global weight scores.

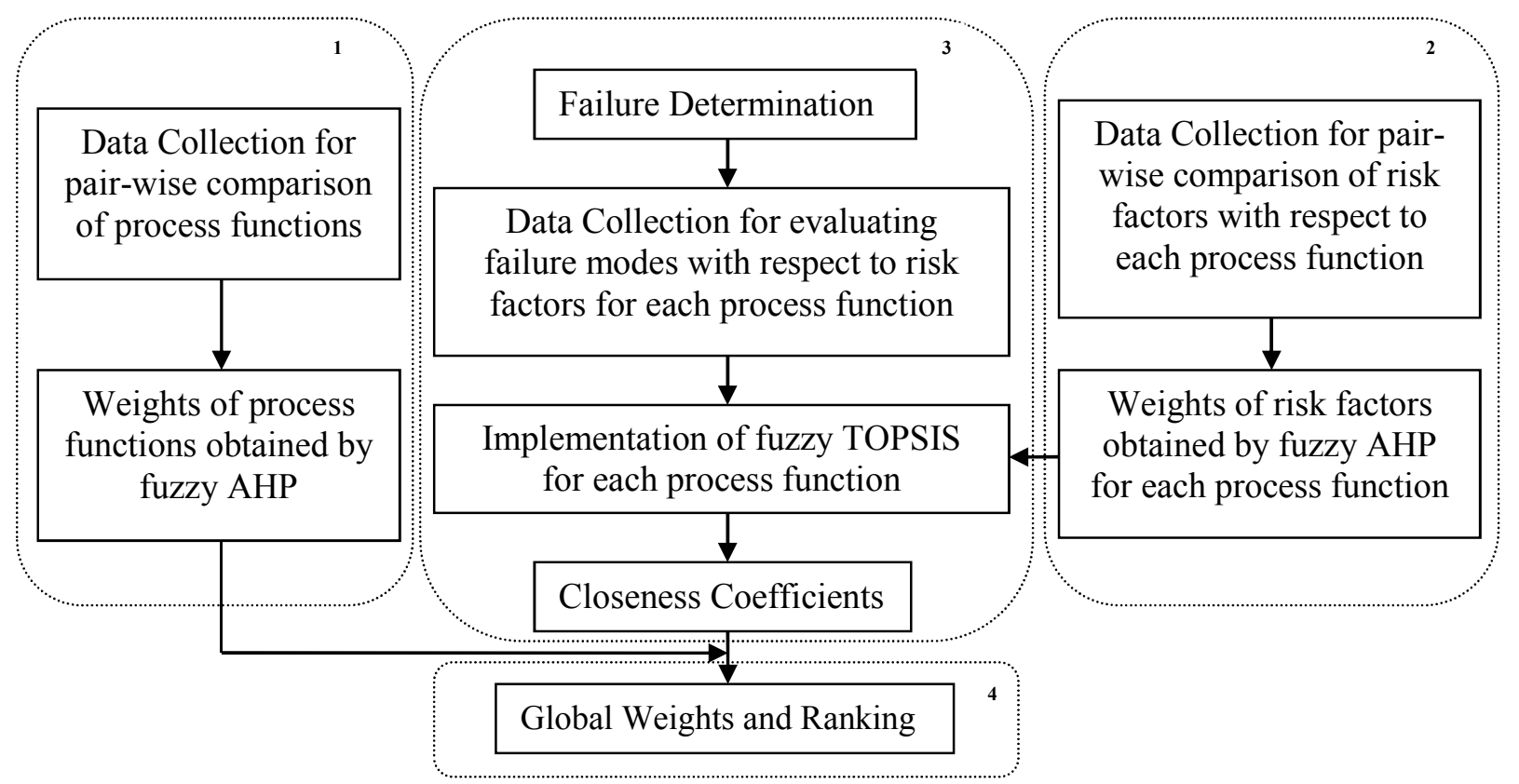

Fig. 1. Flowchart of the Fuzzy PFMEA

\section{An Application to a Spindle Manufacturing Process}

The proposed methodology is applied to a manufacturing SME which was established in 1969 for manufacturing parts and dies for the original equipment and began to manufacture pneumatic brake equipment and brake control systems for trucks and buses in 1980 . The firm modernized its manufacturing technology for manufacturing aluminum injection parts, dies and dies designs for automotive and white-good industries in a $19000 \mathrm{~m}^{2}$ closed area in 2003. The mission of the firm is to achieve die design and die manufacturing by combining scientific methods and technology and overcome the shortcomings in this field in Turkey. Therefore this firm has adopted a quality oriented view.

The methodology mentioned in the paper is utilized in a spindle manufacturing process. In an automobile, the spindle is a part of the suspension system that carries the hub for the wheel and attaches to the upper and lower control arms. The method is focused on the process functions of the spindle manufacturing process and the potential failure modes in the process.

\subsection{Process Functions}

When the manufacturing process is analyzed, nine process functions are defined by the experts of the firm. The flow of these process functions are as the following: incoming material (M1) $\rightarrow$ melting (M2) $\rightarrow$ chemical analysis (M3) $\rightarrow$ die casting (M4) $\rightarrow$ trimming (M5) $\rightarrow$ shot blasting (M6) $\rightarrow$ control (M7) $\rightarrow$ packaging (M8) $\rightarrow$ delivery (M9)

These process functions are defined briefly below.

Incoming Material (M1): It is the process of checking incoming material incase it doesn't provide the predefined specifications. 
Melting (M2): It is the physical process of phase changing of a substance from a solid to a liquid.

Chemical analysis (M3): It is the act of decomposing a substance into its constituent elements.

Die Casting (M4): It is the process of forcing molten metal under high pressure into mold cavities which are machined into dies.

Trimming (M5): It is the process of getting rid of the unwanted pieces at the edges of component.

Control (M7): It is the process of checking whether the result of the prior processes is out of tolerance or not.

Shot Blasting (M6): It is the process of cleaning, and smoothing the surface by forcibly propelling a stream of abrasive material against the surface.

Packaging (M8): It is the process of preparation of goods for distribution, storage, sale, and use. It can be described as a coordinated system of preparing goods for transport, warehousing, logistics, sale, and end use.

Delivery (M9): It is the act or process of transporting goods.

The process functions have different weights of importance in the spindle manufacturing process quality in terms of the potential failure modes. There is a hierarchy shown in Fig. 2 for the goal of the process quality. Process is an activity or a series of activities that use resources to convert input elements into output elements with an added value. The quality of a process depends on the sub-processes or process functions of the process.

The first main step of the proposed methodology is realized by implementing a pair-wise comparison by 4 experts for determining the importance of the process functions in the manufacturing process quality considering the potential failure modes. The evaluations of the experts in linguistic variables for the process functions with respect to their importance are obtained as expressed in Table 3. The findings express that the most important process function is die casting (M4) in the spindle manufacturing process with the importance weight value of 0.207 . The second most important process function is found as incoming material (M1) while the least important process function is appeared as packaging (M8) with the weight value of 0.018 .

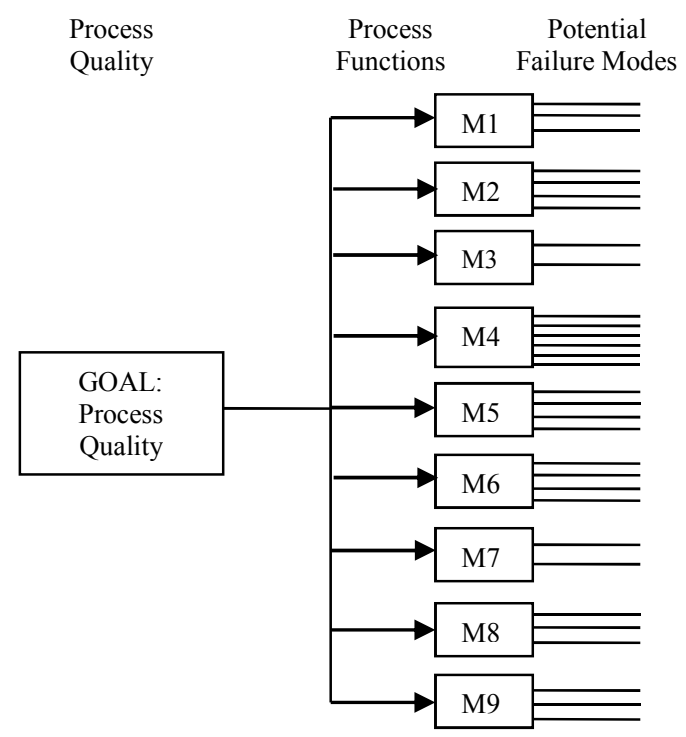

Fig. 2. Manufacturing process quality hierarchy

Table 3. Pair-wise evaluations of experts in linguistic variables for the process functions

\begin{tabular}{|c|c|c|c|c|c|c|c|c|c|c|}
\hline $\begin{array}{l}\text { Process } \\
\text { Functions }\end{array}$ & M1 & M2 & M3 & M4 & M5 & M6 & M7 & M8 & M9 & $\begin{array}{l}\text { Weight Vector } \\
\mathrm{CR}=0.023<0.10\end{array}$ \\
\hline M1 & E,E,E,E & $\begin{array}{l}\text { E,SS, } \\
\text { E,SS }\end{array}$ & $\begin{array}{l}\text { SS,FS, } \\
\text { SS,FS }\end{array}$ & $\begin{array}{l}\text { FW,E, } \\
\text { FW,FS }\end{array}$ & $\begin{array}{l}\text { E,SS, } \\
\text { E,SS }\end{array}$ & $\begin{array}{l}\text { FW,SS, } \\
\text { FW,SS }\end{array}$ & $\begin{array}{l}\text { SS,FS, } \\
\text { FS,SS }\end{array}$ & $\begin{array}{l}\text { VS,AS, } \\
\text { VS,AS }\end{array}$ & $\begin{array}{l}\text { FS,VS, } \\
\text { VS,VS }\end{array}$ & 0.160 \\
\hline M2 & & E,E,E,E & $\begin{array}{l}\text { SS,E, } \\
\text { SS,E }\end{array}$ & $\begin{array}{l}\text { E,FW, } \\
\text { E,FW }\end{array}$ & $\begin{array}{l}\text { E,SW, } \\
\text { E,SW }\end{array}$ & $\begin{array}{l}\text { SS,SW, } \\
\text { SS,SW }\end{array}$ & $\begin{array}{l}\text { SS,FS, } \\
\text { SS,FS }\end{array}$ & $\begin{array}{l}\text { FS,VS, } \\
\text { FS,VS }\end{array}$ & $\begin{array}{l}\text { VS,VS, } \\
\text { VS,VS }\end{array}$ & 0.141 \\
\hline M3 & & & E,E,E,E & $\begin{array}{l}\text { FW,VW, } \\
\text { FW,VW }\end{array}$ & $\begin{array}{l}\text { E,AS, } \\
\text { E,SW }\end{array}$ & $\begin{array}{l}\text { E,SS, } \\
\text { SW,SS }\end{array}$ & $\begin{array}{l}\text { VS,SS, } \\
\text { SS,SS }\end{array}$ & $\begin{array}{c}\text { FW,SS, } \\
\text { VS,SS }\end{array}$ & $\begin{array}{l}\text { SS,SS, } \\
\text { SS,SS }\end{array}$ & 0.106 \\
\hline M4 & & & & E,E,E,E & $\begin{array}{l}\text { SS,AS, } \\
\text { SS,VS }\end{array}$ & $\begin{array}{l}\text { SW,SW, } \\
\text { SW,SW }\end{array}$ & $\begin{array}{l}\text { VS,FS, } \\
\text { AS,FS }\end{array}$ & $\begin{array}{l}\text { VS,VS, } \\
\text { AS,VS }\end{array}$ & $\begin{array}{l}\text { AS,VS, } \\
\text { AS,VS }\end{array}$ & 0.207 \\
\hline M5 & & & & & E,E,E,E & $\begin{array}{c}\text { E,E, } \\
\text { E,SW }\end{array}$ & $\begin{array}{l}\text { SS,FS, } \\
\text { SS,VS }\end{array}$ & $\begin{array}{l}\text { FS,VS, } \\
\text { FS,VS }\end{array}$ & $\begin{array}{l}\text { FS,FS, } \\
\text { FS,FS }\end{array}$ & 0.126 \\
\hline M6 & & & & & & E,E,E,E & $\begin{array}{l}\text { FS,SS, } \\
\text { F S,SS }\end{array}$ & $\begin{array}{l}\text { FS,VS, } \\
\text { FS,VS }\end{array}$ & $\begin{array}{l}\text { FS,FS, } \\
\text { FS,FS }\end{array}$ & 0.144 \\
\hline
\end{tabular}




\begin{tabular}{|c|c|c|c|c|}
\hline M7 & E,E,E,E & $\begin{array}{l}\text { SS,FS, } \\
\text { SS,FS }\end{array}$ & $\begin{array}{l}\text { SS,FS, } \\
\text { SS,FS }\end{array}$ & 0.077 \\
\hline M8 & & E,E,E,E & E,E,E,E & 0.018 \\
\hline M9 & & & E,E,E,E & 0.022 \\
\hline
\end{tabular}

The process functions have different process failure characteristics, so that they should have different importance values for the risk factors severity $(S)$, occurrence $(O)$, and detectability $(D)$. Therefore, in the second main step of the proposed methodology, a Fuzzy FMEA is utilized for each process separately and their $S, O$, and $D$ factors get different importance weights determined by the experts. For obtaining the weight vectors of the each risk factor for each process function, the evaluations of the experts with the pair-wise comparisons in linguistic variables are accomplished for $S, O$, and $D$ (shown in Table 4.). The resulting weights are illustrated in Table 5 for each process function with their $\mathrm{CR}$ values.

Table 4. The pair-wise evaluations of experts in linguistic variables for $\mathrm{S}, \mathrm{O}$ and $\mathrm{D}$ risk factors for each process function

\begin{tabular}{|c|c|c|c|c|}
\hline Incoming Material & $\mathrm{S}$ & $\mathrm{O}$ & $\mathrm{D}$ & Weight Vector $\mathrm{CR}=0.083$ \\
\hline $\mathrm{S}$ & $(\mathrm{E}, \mathrm{E}, \mathrm{E}, \mathrm{E})$ & $(\mathrm{FS}, \mathrm{FS}, \mathrm{VS}, \mathrm{VS})$ & (VS,SS,VS,VS) & 0.624 \\
\hline $\mathrm{O}$ & & $(\mathrm{E}, \mathrm{E}, \mathrm{E}, \mathrm{E})$ & (SS,FS,FW,SS) & 0.219 \\
\hline $\mathrm{D}$ & & & (EEEE) & 0.157 \\
\hline Melting & $\mathrm{S}$ & $\mathrm{O}$ & $\mathrm{D}$ & Weight Vector $\mathrm{CR}=0.051$ \\
\hline $\mathrm{S}$ & $(\mathrm{E}, \mathrm{E}, \mathrm{E}, \mathrm{E})$ & $(\mathrm{SS}, \mathrm{SS}, \mathrm{FS}, \mathrm{SS})$ & $(\mathrm{E}, \mathrm{FS}, \mathrm{SW}, \mathrm{E})$ & 0.389 \\
\hline $\mathrm{O}$ & & $(\mathrm{E}, \mathrm{E}, \mathrm{E}, \mathrm{E})$ & $(\mathrm{FW}, \mathrm{E}, \mathrm{E}, \mathrm{FW})$ & 0.242 \\
\hline $\mathrm{D}$ & & & $(\mathrm{E}, \mathrm{E}, \mathrm{E}, \mathrm{E})$ & 0.369 \\
\hline Chemical Analysis & $\mathrm{S}$ & $\mathrm{O}$ & $\mathrm{D}$ & Weight Vector $\mathrm{CR}=0.089$ \\
\hline $\mathrm{S}$ & $(\mathrm{E}, \mathrm{E}, \mathrm{E}, \mathrm{E})$ & (VS,FS,SW,FW) & $(\mathrm{SS}, \mathrm{SS}, \mathrm{SS}, \mathrm{E})$ & 0.395 \\
\hline $\mathrm{O}$ & & $(\mathrm{E}, \mathrm{E}, \mathrm{E}, \mathrm{E})$ & $(\mathrm{FS}, \mathrm{E}, \mathrm{E}, \mathrm{E})$ & 0.336 \\
\hline $\mathrm{D}$ & & & $(\mathrm{E}, \mathrm{E}, \mathrm{E}, \mathrm{E})$ & 0.269 \\
\hline Die Casting & $\mathrm{S}$ & $\mathrm{O}$ & $\mathrm{D}$ & Weight Vector $\mathrm{CR}=0.045$ \\
\hline $\mathrm{S}$ & $(\mathrm{E}, \mathrm{E}, \mathrm{E}, \mathrm{E})$ & $(\mathrm{FS}, \mathrm{E}, \mathrm{SS}, \mathrm{E})$ & $(\mathrm{E}, \mathrm{E}, \mathrm{FS}, \mathrm{SW})$ & 0.402 \\
\hline $\mathrm{O}$ & & $(\mathrm{E}, \mathrm{E}, \mathrm{E}, \mathrm{E})$ & $(\mathrm{FW}, \mathrm{E}, \mathrm{E}, \mathrm{SS})$ & 0.262 \\
\hline $\mathrm{D}$ & & & $(\mathrm{E}, \mathrm{E}, \mathrm{E}, \mathrm{E})$ & 0.336 \\
\hline Trimming & $\mathrm{S}$ & $\mathrm{O}$ & $\mathrm{D}$ & Weight Vector $\mathrm{CR}=0.067$ \\
\hline $\mathrm{S}$ & $(\mathrm{E}, \mathrm{E}, \mathrm{E}, \mathrm{E})$ & (SS,FS,SW,E) & (FS,E,SW,FW) & 0.358 \\
\hline $\mathrm{O}$ & & $(\mathrm{E}, \mathrm{E}, \mathrm{E}, \mathrm{E})$ & (SS,E,FW,SW) & 0.284 \\
\hline $\mathrm{D}$ & & & $(\mathrm{E}, \mathrm{E}, \mathrm{E}, \mathrm{E})$ & 0.358 \\
\hline Shot Blasting & $\mathrm{S}$ & $\mathrm{O}$ & $\mathrm{D}$ & Weight Vector $\mathrm{CR}=0.073$ \\
\hline $\mathrm{S}$ & $(\mathrm{E}, \mathrm{E}, \mathrm{E}, \mathrm{E})$ & $(\mathrm{E}, \mathrm{SS}, \mathrm{FW}, \mathrm{SW})$ & (SS,FS,SS,E) & 0.332 \\
\hline $\mathrm{O}$ & & $(\mathrm{E}, \mathrm{E}, \mathrm{E}, \mathrm{E})$ & $(\mathrm{SS}, \mathrm{FS}, \mathrm{SW}, \mathrm{FW})$ & 0.355 \\
\hline $\mathrm{D}$ & & & $(\mathrm{E}, \mathrm{E}, \mathrm{E}, \mathrm{E})$ & 0.313 \\
\hline Control & $\mathrm{S}$ & $\mathrm{O}$ & $\mathrm{D}$ & Weight Vector $\mathrm{CR}=0.042$ \\
\hline $\mathrm{S}$ & $(\mathrm{E}, \mathrm{E}, \mathrm{E}, \mathrm{E})$ & (FS,FS,SS,FS) & (FS,SS,FS,SS) & 0.470 \\
\hline $\mathrm{O}$ & & $(\mathrm{E}, \mathrm{E}, \mathrm{E}, \mathrm{E})$ & $(\mathrm{SS}, \mathrm{E}, \mathrm{E}, \mathrm{SW})$ & 0.259 \\
\hline $\mathrm{D}$ & & & $(\mathrm{E}, \mathrm{E}, \mathrm{E}, \mathrm{E})$ & 0.271 \\
\hline Packaging & $\mathrm{S}$ & $\mathrm{O}$ & $\mathrm{D}$ & Weight Vector $\mathrm{CR}=0.093$ \\
\hline $\mathrm{S}$ & $(\mathrm{E}, \mathrm{E}, \mathrm{E}, \mathrm{E})$ & $(\mathrm{SS}, \mathrm{SS}, \mathrm{SW}, \mathrm{E})$ & $(\mathrm{FS}, \mathrm{FS}, \mathrm{FW}, \mathrm{FW})$ & 0.335 \\
\hline $\mathrm{O}$ & & $(\mathrm{E}, \mathrm{E}, \mathrm{E}, \mathrm{E})$ & $(\mathrm{E}, \mathrm{E}, \mathrm{FS}, \mathrm{FS})$ & 0.363 \\
\hline $\mathrm{D}$ & & & $(\mathrm{E}, \mathrm{E}, \mathrm{E}, \mathrm{E})$ & 0.302 \\
\hline Delivery & $\mathrm{S}$ & $\mathrm{O}$ & $\mathrm{D}$ & Weight Vector $C R=0.036$ \\
\hline $\mathrm{S}$ & $(\mathrm{E}, \mathrm{E}, \mathrm{E}, \mathrm{E})$ & $(\mathrm{E}, \mathrm{FW}, \mathrm{SW}, \mathrm{FW})$ & $(\mathrm{E}, \mathrm{SW}, \mathrm{FW}, \mathrm{SW})$ & 0.234 \\
\hline $\mathrm{O}$ & & $(\mathrm{E}, \mathrm{E}, \mathrm{E}, \mathrm{E})$ & $(\mathrm{E}, \mathrm{E}, \mathrm{E}, \mathrm{SW})$ & 0.400 \\
\hline $\mathrm{D}$ & & & $(\mathrm{E}, \mathrm{E}, \mathrm{E}, \mathrm{E})$ & 0.367 \\
\hline
\end{tabular}


The findings demonstrate that the importance of severity is the greatest in incoming material process function with 0.624 while it is the smallest in delivery with the value of 0.234 . The process function delivery has also the biggest value of occurrence factor. While severity is so important for the potential failure modes in incoming material, detectability factor has the least importance in this process function. Shot blasting process function has the risk factors most balanced with close weight of importance values.

Table 5. The resulting weights for each process function

\begin{tabular}{ccccc}
\hline Process & \multicolumn{4}{c}{ Weight Vector of the Process Functions } \\
\cline { 2 - 5 } Functions & S & O & D & CR \\
\hline M1 & 0.624 & 0.219 & 0.157 & 0.083 \\
M2 & 0.389 & 0.242 & 0.369 & 0.051 \\
M3 & 0.395 & 0.336 & 0.269 & 0.089 \\
M4 & 0.402 & 0.262 & 0.336 & 0.045 \\
M5 & 0.358 & 0.284 & 0.358 & 0.067 \\
M6 & 0.332 & 0.355 & 0.313 & 0.073 \\
M7 & 0.470 & 0.259 & 0.271 & 0.042 \\
M8 & 0.335 & 0.363 & 0.302 & 0.093 \\
M9 & 0.234 & 0.400 & 0.367 & 0.036 \\
\hline
\end{tabular}

\subsection{Potential Failure Modes}

In every process there are several critical potential failure modes determined by the experts in the process functions. The third step of the proposed methodology begins with determining the potential failure modes by the experts. These failures are shown in Table 6 for each process function. For instance chemical analysis process function has two critical potential failure modes while die casting process function has 6 potential failure modes.

Table 6. Potential failure modes

\begin{tabular}{ll}
\hline M1 & $\frac{\text { Chemical comp. Out of standard }\left(\mathrm{M}_{11}\right)}{\text { Mistake on having sample and doing analyze }\left(\mathrm{M}_{12}\right)}$ \\
\hline & $\frac{\text { Deviation of the spectrometer settings }\left(\mathrm{M}_{13}\right)}{\text { Msing of too much return material }\left(\mathrm{M}_{21}\right)}$ \\
\hline & $\frac{\text { Loading wrong material into furnace }\left(\mathrm{M}_{22}\right)}{\text { Wrong temperature in melting furnace }\left(\mathrm{M}_{23}\right)}$ \\
\hline
\end{tabular}

Using the sama transport crucible for different alloy types $\left(\mathrm{M}_{24}\right)$

\begin{tabular}{|c|c|}
\hline \multirow{2}{*}{ M3 } & Mistake on having sample and doing analyze $\left(\mathrm{M}_{31}\right)$ \\
\hline & Deviation of the spectrometer settings $\left(\mathrm{M}_{32}\right)$ \\
\hline \multirow{6}{*}{ M4 } & Porosity $\left(\mathrm{M}_{41}\right)$ \\
\hline & Insufficient cooling time $\left(\mathrm{M}_{42}\right)$ \\
\hline & Incomplete filling of cavities $\left(\mathrm{M}_{43}\right)$ \\
\hline & Blister $\left(\mathrm{M}_{44}\right)$ \\
\hline & Part of casting is missing $\left(\mathrm{M}_{45}\right)$ \\
\hline & Excessive flash $\left(\mathrm{M}_{46}\right)$ \\
\hline \multirow{4}{*}{ M5 } & Burrs on surface $\left(\mathrm{M}_{51}\right)$ \\
\hline & Broken spindle $\left(\mathrm{M}_{52}\right)$ \\
\hline & Broken pins $\left(\mathrm{M}_{53}\right)$ \\
\hline & Negative breaking surface $\left(\mathrm{M}_{54}\right)$ \\
\hline \multirow{4}{*}{ M6 } & Burrs on the surfaces $\left(\mathrm{M}_{61}\right)$ \\
\hline & Colour changes on the surfaces $\left(\mathrm{M}_{62}\right)$ \\
\hline & Non-homogenous surface roughness $\left(\mathrm{M}_{63}\right)$ \\
\hline & Surface roughness higher than Rz16 $\left(\mathrm{M}_{64}\right)$ \\
\hline \multirow{2}{*}{ M7 } & Defective spindle $\left(\mathrm{M}_{71}\right)$ \\
\hline & Out of tolerance $\left(\mathrm{M}_{72}\right)$ \\
\hline \multirow{3}{*}{ M8 } & Wrong quantities in the boxes $\left(\mathrm{M}_{81}\right)$ \\
\hline & Wrong labels on boxes $\left(\mathrm{M}_{82}\right)$ \\
\hline & Broken pinion in the internal transport $\left(\mathrm{M}_{83}\right)$ \\
\hline \multirow{3}{*}{ M9 } & Non Conformity to deadline $\left(\mathrm{M}_{91}\right)$ \\
\hline & Wrong product/order delivery $\left(\mathrm{M}_{92}\right)$ \\
\hline & Missing/Wrong Documents $\left(\mathrm{M}_{93}\right)$ \\
\hline
\end{tabular}

After the determination of weight vectors of $S, O$ and $D$ for each process function, fuzzy TOPSIS is utilized and the potential failure modes are evaluated with respect to $S, O$ and $D$ according to their belonging process functions. Table 7 shows the complete evaluations of three experts for potential failure modes with respect to the risk factors. For example in control process function, the potential failure mode of defective spindle is evaluated as Medium Good (MG), Fair (F) and Fair (F) respectively for $\mathrm{S}, \mathrm{O}$ and $\mathrm{D}$ by expert 1 . Also again in control process function, the $S$ of the potential failure mode of defective spindle is evaluated as Medium Good (MG), Medium Good (MG), and Good $(\mathrm{G})$ by the experts.

Table 7. The evaluations of experts in linguistic variables for potential failure modes with respect to $S, O$ and $D$ for each process function

\begin{tabular}{llll}
\hline $\mathrm{M} 1$ & $\mathrm{~S}$ & $\mathrm{O}$ & $\mathrm{D}$ \\
\hline
\end{tabular}




\begin{tabular}{cccc}
\hline $\mathrm{M}_{11}$ & G,MG,G & MP,MP,P & P,MP,F \\
$\mathrm{M}_{12}$ & MG,MG,VG & F,MP,MP & MP,MP,MP \\
$\mathrm{M}_{13}$ & MG,MG,MG & MP,MP,P & P,MP,MP \\
\hline & & & \\
\hline $\mathrm{M} 2$ & $\mathrm{~S}$ & $\mathrm{O}$ & $\mathrm{D}$ \\
\hline $\mathrm{M}_{21}$ & $\mathrm{VG}, \mathrm{G}, \mathrm{VG}$ & P,P,P & MP,MP,MP \\
$\mathrm{M}_{22}$ & MG,G,G & MP,MP,P & P,MP,P \\
$\mathrm{M}_{23}$ & $\mathrm{MG}, \mathrm{G}, \mathrm{G}$ & P,P,P & P,P,MP \\
$\mathrm{M}_{24}$ & MG,G,MG & MP,MP,P & P,P,MP \\
\hline
\end{tabular}

\begin{tabular}{lccc}
\hline M3 & S & O & D \\
\hline M $_{31}$ & MG,MG,G & P,P,P & MP,MP,MP \\
M $_{32}$ & MG,G,MG & P,MP,VP & MP,P,F \\
\hline
\end{tabular}

\begin{tabular}{cccc}
\hline M4 & S & O & D \\
\hline $\mathrm{M}_{41}$ & G,G,VG & F,F,MG & P,P,P \\
$\mathrm{M}_{42}$ & VG,G,G & F,F,G & VP,P,VP \\
$\mathrm{M}_{43}$ & G,G,G & P,MP,MP & VP,P,P \\
$\mathrm{M}_{44}$ & VG,G,MG & MP,MP,F & P,P,VP \\
$\mathrm{M}_{45}$ & G,G,VG & MG,F,MP & VP,P,P \\
$\mathrm{M}_{46}$ & VG,G,G & G,MG,G & P,P,P \\
\hline
\end{tabular}

\begin{tabular}{lccc}
\hline M5 & S & O & D \\
\hline $\mathrm{M}_{51}$ & VG,G,VG & G,G,G & P,P,MP \\
$\mathrm{M}_{52}$ & MG,MG,MG & G,G,MG & P,P,P \\
$\mathrm{M}_{53}$ & MG,MG,MG & F,F,F & P,P,P \\
$\mathrm{M}_{54}$ & MG,MG,G & MG,F,F & P,P,P \\
\hline
\end{tabular}

\begin{tabular}{lccc}
\hline M6 & S & O & D \\
\hline $\mathrm{M}_{61}$ & F,MG,MG & MP,MP,MP & VP,P,VP \\
$\mathrm{M}_{62}$ & MG,F,MG & MP,F,F & VP,VP,P \\
\hline
\end{tabular}

\begin{tabular}{|c|c|c|c|}
\hline $\mathrm{M}_{63}$ & $\mathrm{MG}, \mathrm{F}, \mathrm{MG}$ & F,MP,MP & VP,P,P \\
\hline $\mathrm{M}_{64}$ & $\mathrm{G}, \mathrm{MG}, \mathrm{G}$ & $\mathrm{F}, \mathrm{MG}, \mathrm{F}$ & $\mathrm{P}, \mathrm{P}, \mathrm{P}$ \\
\hline M7 & $\mathrm{S}$ & $\mathrm{O}$ & D \\
\hline $\mathrm{M}_{71}$ & $\mathrm{MG}, \mathrm{MG}, \mathrm{G}$ & $\mathrm{F}, \mathrm{MG}, \mathrm{F}$ & $\mathrm{F}, \mathrm{MP}, \mathrm{MG}$ \\
\hline $\mathrm{M}_{72}$ & $\mathrm{G}, \mathrm{G}, \mathrm{G}$ & MP,F,MP & $\mathrm{P}, \mathrm{P}, \mathrm{F}$ \\
\hline M8 & $\mathrm{S}$ & $\mathrm{O}$ & $\mathrm{D}$ \\
\hline $\mathrm{M}_{81}$ & $\mathrm{~F}, \mathrm{MG}, \mathrm{F}$ & $\mathrm{F}, \mathrm{F}, \mathrm{F}$ & MP,MP,F \\
\hline $\mathrm{M}_{82}$ & $\mathrm{~F}, \mathrm{~F}, \mathrm{~F}$ & $\mathrm{MP}, \mathrm{F}, \mathrm{MG}$ & F,MG,G \\
\hline $\mathrm{M}_{83}$ & MG,G,G & MP,F,MP & MG,MG,MG \\
\hline
\end{tabular}

\begin{tabular}{lccc}
\hline M9 & S & O & D \\
\hline M $_{91}$ & P,MP,MP & F,MP,F & MP,MP,F \\
M $_{92}$ & G,MG,G & MP,MP,F & F,MP,F \\
M $_{93}$ & MG,G,G & P,P,P & MP,P,F \\
\hline
\end{tabular}

In the fourth and final step, closeness coefficient values of each failure mode are multiplied by the weights of the process functions to find the global weights of the failure modes. Subsequently, the global weights are ranked. The final results consisting closeness coefficients, global weights and rankings of potential failure modes are displayed in Table 8 . The results show that the most important critical failure mode for the spindle manufacturing process is excessive flash in die casting process. The second most important failure mode appears to be porosity again in die casting process. The potential failure mode with the least importance is the wrong quantities in the boxes come out in the packaging process.

Table 8 . The importance of each potential failure mode

\begin{tabular}{clccc}
\hline \multirow{3}{*}{ Processes } & Failure Modes & CCs & $\begin{array}{c}\text { Global } \\
\text { Importance }\end{array}$ & Ranking \\
\hline \multirow{3}{*}{ Incoming Material } & Chemical comp. Out of standart & 0.246 & 0.047 & 8 \\
\cline { 2 - 5 } & Mistake on having sample and doing analyse & 0.256 & 0.049 & 6 \\
\cline { 2 - 5 } & Deviation of the spectrometer settings & 0.218 & 0.042 & 10 \\
\hline \multirow{5}{*}{ Melting } & Using of too much return material & 0.234 & 0.040 & 12 \\
\cline { 2 - 5 } & Loading wrong material into furnace & 0.212 & 0.036 & 13 \\
\cline { 2 - 5 } & Wrong temperature in melting furnace & 0.193 & 0.032 & 16 \\
\cline { 2 - 5 } & Using the sama transport crucible for & & & \\
& different alloy types & 0.206 & 0.035 & 14 \\
\hline \multirow{2}{*}{ Chemical Analysis } & Mistake on having sample and doing analyse & 0.230 & 0.029 & 21 \\
\cline { 2 - 5 } & Deviation of the spectrometer settings & 0.235 & 0.030 & 20 \\
\hline \multirow{2}{*}{ Die Casting } & Porosity & 0.237 & 0.059 & 2 \\
\cline { 2 - 5 } & Insufficient cooling time & 0.212 & 0.053 & 4 \\
\cline { 2 - 5 } & Incomplete filling of cavities & 0.191 & 0.047 & 7 \\
\cline { 2 - 5 } & & & &
\end{tabular}




\begin{tabular}{cllll} 
& Blister & 0.198 & 0.049 & 5 \\
\cline { 2 - 5 } & Part of casting is missing & 0.217 & 0.054 & 3 \\
\cline { 2 - 5 } Trimming & Excessive flash & 0.257 & 0.064 & 1 \\
\hline \multirow{5}{*}{ Shot Blasting } & 0.265 & 0.040 & 11 \\
\cline { 2 - 5 } & Burrs on surface & 0.218 & 0.032 & 15 \\
\cline { 2 - 5 } & Broken spindle & 0.190 & 0.029 & 22 \\
\cline { 2 - 5 } & Broken pins & 0.202 & 0.030 & 19 \\
\cline { 2 - 5 } & Negative breaking surface & 0.158 & 0.028 & 23 \\
\cline { 2 - 5 } & Burrs on the surfaces & 0.177 & 0.030 & 18 \\
\cline { 2 - 5 } Control & Non-homogenous surface roughness & 0.181 & 0.031 & 17 \\
\cline { 2 - 5 } & Surface roughness higher than Rz16 & 0.242 & 0.042 & 9 \\
\hline \multirow{3}{*}{ Packaging } & Defective spindle & 0.252 & 0.023 & 24 \\
\cline { 2 - 5 } & Out of tolerance & 0.217 & 0.020 & 25 \\
\hline \multirow{3}{*}{ Delivery } & Wrong quantities in the boxes & 0.201 & 0.005 & 31 \\
\cline { 2 - 5 } & Wrong labels on boxes & 0.228 & 0.005 & 29 \\
\cline { 2 - 5 } & Broken pinion in the internal transport & 0.242 & 0.005 & 27 \\
\cline { 2 - 5 } & Non Conformity to deadline & 0.236 & 0.005 & 28 \\
\cline { 2 - 5 } & Wrong product/order delivery & 0.168 & 0.005 & 30 \\
\cline { 2 - 5 } & Missing/Wrong Documents & & & \\
\hline & & & 0.194 & 26 \\
\hline
\end{tabular}

\subsection{Sensitivity Analysis}

In this subsection, we observe if the ranking of potential failure modes are robust or too sensitive to the changes in the weights of the manufacturing processes. A sensitivity analysis by changing the weights of manufacturing processes is calculated according to information given in Table 9. The results for ranking the PFMs of the manufacturing processes for different cases are shown in Fig. 3.

Table 9. The weights of the manufacturing processes with respect to the considered cases

\begin{tabular}{llllll}
\hline & Case & Case1 & Case2 & Case3 & Case4 \\
\hline M1 & 0.160 & 0.150 & 0.111 & 0.100 & 0.050 \\
M2 & 0.141 & 0.150 & 0.111 & 0.100 & 0.150 \\
M3 & 0.106 & 0.150 & 0.111 & 0.080 & 0.150 \\
M4 & 0.207 & 0.150 & 0.111 & 0.170 & 0.150 \\
M5 & 0.126 & 0.100 & 0.111 & 0.100 & 0.150 \\
M6 & 0.144 & 0.100 & 0.111 & 0.150 & 0.170 \\
M7 & 0.077 & 0.100 & 0.111 & 0.100 & 0.080 \\
M8 & 0.018 & 0.050 & 0.111 & 0.100 & 0.050 \\
M9 & 0.022 & 0.050 & 0.111 & 0.100 & 0.050 \\
\hline
\end{tabular}

According to the sensitivity analysis results, as the importance of all manufacturing processes are same, Burrs on surfaces, one of the potential failure mode of Shot Blasting manufacturing process, is ranked first and Excessive flash, one of the potential failure mode of Die Casting manufacturing process, is ranked second. In the other three cases, Excessive flash is ranked first. So it can be considered that Excessive flash is the most important potential failure mode among the others. On the other hand a similar result can be reasoned as Missing/Wrong Documents, one of the potential failure mode of Delivery manufacturing process, is the least important potential failure mode.

\section{Conclusion}

PFMEA, designed to provide information for risk management decision-making in any process, is a widely used engineering technique in industries. In PFMEA potential failure modes are determined and can be evaluated by risk factors named severity, occurrence, and detection. In a typical PFMEA, the risk priority number of each failure mode is obtained by the multiplication of crisp values of the risk factors.

Due to the criticisms in literature for RPN calculation uses the multiplication method, a fuzzy hybrid approach is considered for PFMEA by its superiority over the traditional approach. This study firstly applies a model of Chen's fuzzy TOPSIS integrated with Buckley's fuzzy AHP separately for each process function. Later the closeness coefficients are multiplied by the weights of the process functions for finding the global weight scores. Finally the potential failures are ranked according to their global weight scores. 


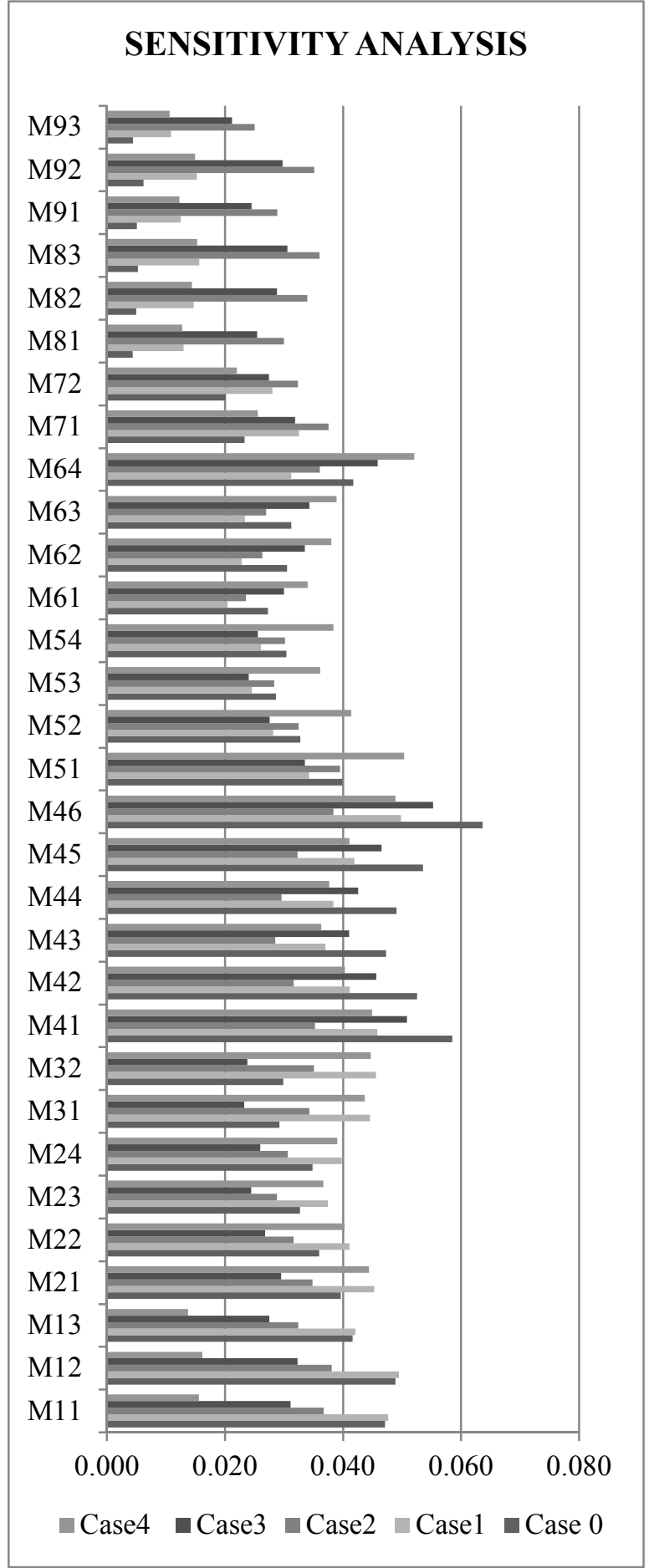

Fig. 3. Sensitivity analysis

In this study a spindle manufacturing process is considered as an application case study that demonstrated the applicability of the proposed hybrid fuzzy model. By regarding the sensitivity analysis, Excessive flash, one of the potential failure mode of Die Casting manufacturing process, is determined as the most important potential failure mode whereas Missing/Wrong Documents, one of the potential failure mode of Delivery manufacturing process, is determined as the least important potential failure mode.

For further research, we suggest other multi-criteria methods like ELECTRE, VIKOR, or Utility Models to be used and the obtained results be compared with the results of this paper.

\section{References}

1. M. Pacella, Q. Semeraro and A. Anglani, Adaptive Resonance Theory-based neural algorithms for manufacturing process quality control. International Journal of Production Research 42(21) (2004) 45814607.

2. M. Pacella and Q. Semeraro, Understanding ART-based neural algorithms as statistical tools for manufacturing process quality control. Engineering Applications of Artificial Intelligence 18 (2005) 645-662.

3. K. S. Chin, A. Chan and J. B. Yang, Development of a fuzzy FMEA based product design system. International Journal of Advanced Manufacturing Technology $\mathbf{3 6}$ (2008) 633-649.

4. D. H. Stamatis, Failure mode and effect analysis: FMEA from theory to execution. (Milwaukee, WI: ASQC Quality Press 1995)

5. C. L. Chang, C. C.Wei and Y. H. Lee, Failure mode and effects analysis using fuzzy method and grey theory. Kybernetes 28 (1999) 1072-1080.

6. W. Gilchrist, Modeling failure mode and effect analysis. International Journal of Quality \& Reliability Management 10(5) (1993) 16-23.

7. A. Pillay and J. Wang, Modified failure mode and effects analysis using approximate reasoning. Reliability Engineering \& System Safety 79 (2003) 69-85.

8. M. Ben-Daya and A. Raouf, A revised failure mode and effects analysis model. International Journal of Quality \& Reliability Management 13(1) (1996) 43-47.

9. J. B. Bowles, An assessment of PRN prioritization in a failure modes effects and criticality analysis. Journal of the IEST 47 (2004) 51-56.

10. M. Braglia and M. Bevilacqua, Fuzzy modeling and analytic hierarchy processing as a means to quantify risk levels associated with failure modes in production systems. Technology, Law and Insurance 5(3-4) (2000) 125-134.

11. M. Braglia, M. Frosolini and R. Montanari, Fuzzy TOPSIS Approach for Failure Mode, Effects and Criticality Analysis. Quality and Reliability Engineering International 19 (2003) 425-443. 
12. C. L. Chang, P. H Liu and C. C. Wei, Failure mode and effects analysis using grey theory. Integrated Manufacturing Systems 12(3) (2001) 211-216.

13. N. R. Sankar and B. S. Prabhu, Modified approach for prioritization of failures in a system failure mode and effects analysis. International Journal of Quality \& Reliability Management 18(3) (2001) 324-335.

14. Y.-M. Wang, K.-S. Chin, G. K. K Poon and J.-B. Yang, Risk evaluation in failure mode and effects analysis using fuzzy weighted geometric mean. Expert Systems with Applications 36 (2009) 1195-1207.

15. K. M. Tay, and C. P. Lim, Fuzzy FMEA with a guided rules reduction system for prioritization of failures. International Journal of Quality \& Reliability Management 23(8) (2006) 1047-1066.

16. K. Xu, L. C.Tang, M. Xie, S. L. Ho and M. L. Zhu, Fuzzy assessment of FMEA for engine systems. Reliability Engineering \& System Safety 75 (2002) 1729.

17. J. B. Bowles and C. E. Pelaez, Fuzzy logic prioritization of failures in a system failure mode, effects and criticality analysis. Reliability Engineering and System Safety 50 (1995) 203-213.

18. J. J. Buckley, Fuzzy hierarchical analysis, Fuzzy Sets and Systems 17 (1985) 233-247.

19. C. Chen, Extensions of the TOPSIS for group decisionmaking under fuzzy environment, Fuzzy Sets and Systems 114 (2000) 1-9.

20. A. C. F. Guimarães and C. M. F. Lapa, Fuzzy inference to risk assessment on nuclear engineering systems. Applied Soft Computing 7 (2007) 17-28.

21. A. C. F. Guimarães and C. M. F. Lapa, Fuzzy FMEA applied to PWR chemical and volume control system. Progress in Nuclear Energy 44(3) (2004) 191-213.

22. R. K. Sharma, D. Kumarand P Kumar, Systematic failure mode effect analysis (FMEA) using fuzzy linguistic modeling. International Journal of Quality \& Reliability Management 22(9) (2005) 986-1004.

23. M. Braglia, MAFMA: Multi-attribute failure mode analysis. International Journal of Quality and Reliability Management 17(9) (2000) 1017-1033.

24. A. H. Hua,. C.-W. Hsu, T.-C. Kuo and W.-C. Wua, Risk evaluation of green components to hazardous substance using FMEA and FAHP Expert Systems with Applications 36 (2009) 7142-7147.

25. T. L. Saaty, The Analytic Hierarchy Process (New York: McGraw-Hill.Baker, 1980).

26. T. C. Wang and Y. H. Chen, Applying consistent fuzzy preference relations to partnership selection, International Journal of Management Science 35 (2007) 384-388.

27. N. Y. Seçme, A. Bayrakdaroğlu and C. Kahraman, Fuzzy performance evaluation in Turkish Banking Sector using Analytic Hierarchy Process and TOPSIS, Experts Systems with Applications 36 (2009) 11699-11709.
28. C. Kahraman, U. Cebeci and Z. Ulukan, Multi-criteria supplier selection using fuzzy AHP, Logistics Information Management 16(6) (2003) 382-394.

29. P. M. J. Laarhoven and W. Pedrycz, A fuzzy extension of Saaty's priority theory, Fuzzy Sets and Systems 11 (1983) 229-241.

30. D. Y. Chang, Applications of the extent analysis method on fuzzy AHP, European Journal of Operational Research 95(3) (1996) 649-655.

31. C. Kahraman, Z. Ulukan and E. Tolga, A fuzzy weighted evaluation method using objective and subjective measures, in Proceedings of the international ICSC symposium on engineering of intelligent systems (1 1998) pp. $57-63$.

32. O. Kulak and C. Kahraman, Fuzzy multi attribute selection among transportation companies using axiomatic design and analytic hierarchy process, Information Sciences 170 (2005) 191-210.

33. C. L. Hwang and K. Yoon, Multiple attributes decision making methods and applications (Berlin: Springer 1981).

34. M. Ekmekçioğlu, T. Kaya and C. Kahraman, Fuzzy Multicriteria Disposal Method and Site Selection for Municipal Solid Waste, Waste Management 30 (2010) 1729-1736.

35. S. J. Chen and C. L. Hwang, Fuzzy multi attribute decision making, (lecture notes in economics and mathematical system series) (Springer-Verlag New York, vol. 375,1992$)$

36. E. Triantaphyllou, and C. L. Lin., Development and evaluation of five fuzzy multi- attribute decision making methods, International Journal of Approximate Reasoning 14 (1996) 281-310.

37. T. Chu, Selecting plant location via a fuzzy TOPSIS approach, International Journal of Advanced Manufacturing Technology 20 (2002) 859-864.

38. T. Chu and Y. Lin, Improved extensions of the TOPSIS for group decision making under fuzzy environment, Journal of Information and Optimization Sciences $\mathbf{2 3}$ (2002) 273-286.

39. G. R. Jahanshahloo, L. Hosseinzadeh and M. Izadikhah, Extension of the TOPSIS method for decision-making problems with fuzzy data, Applied Mathematics and Computation 181 (2006) 1544-1551.

40. T. C. Chu and Y. C. Lin, An interval arithmetic based fuzzy TOPSIS model, Expert Systems with Applications 36 (2009) 10870-10876.

41. D. Yong, Plant Location Selection Based on Fuzzy TOPSIS, International Journal of Advanced Manufacturing Technologies 28 (2006) 839-844.

42. C.-T. Chena, C.-T. Lin and S.-F. Huangb, A fuzzy approach for supplier evaluation and selection in supply chain management, International Journal of Production Economics (2006), 289-301.

43. C. Kahraman, S. Çevik, N. Y. Ateş and M. Gülbay, Fuzzy multi-criteria evaluation of industrial robotic 
systems, Computers \& Industrial Engineering 52 (2007) 414-433.

44. T. Kaya and C. Kahraman, Multicriteria decision making in energy planning using a modified fuzzy TOPSIS methodology, Expert Systems with Applications $\mathbf{3 8}$ (2011) 6577-6585.

45. S. Kim, K. Lee, J. K. Cho and C. O. Kim, Agent-based diffusion model for an automobile market with fuzzy TOPSIS-based product adoption process, Expert Systems with Applications 38 (2011) 7270-7276.

46. Y. Dong, W.-C. Hong, and Y. Xu and S. Yu, Selecting the individual numerical scale and prioritization method in the analytic hierarchy process: A 2-tuple fuzzy linguistic approach, IEEE Transactions on Fuzzy Systems 19(1) (2011) 13-26.

47. Y. Dong, Y. Xu, H. Li, M and M. Dai, A Comparative study of the numerical scales and the prioritization methods in AHP, European Journal of Operational Research 186 (2008) 229-242.

48. T. Kaya and C. Kahraman, An integrated fuzzy AHPELECTRE methodology for environmental impact assessment, Expert Systems with Applications 38(7) (2011) 8553-8562. 